\title{
Analysis of Illegal Parking Behavior in Jeddah
}

\section{Mohammed Aljoufie}

Department of Urban and Regional Planning, Faculty of Environmental Design, King Abdulaziz University, Jeddah, Saudi Arabia

Email: maljufie@kau.edu.sa

How to cite this paper: Aljoufie, M. (2016). Analysis of Illegal Parking Behavior in Jeddah. Current Urban Studies, 4, 393-408. http://dx.doi.org/10.4236/cus.2016.44026

Received: September 16, 2016

Accepted: October 16, 2016

Published: October 19, 2016

Copyright () 2016 by author and Scientific Research Publishing Inc. This work is licensed under the Creative Commons Attribution International License (CC BY 4.0).

http://creativecommons.org/licenses/by/4.0/ (c) (i) Open Access

\begin{abstract}
Parking spaces play a vital role in the transportation system. Parking policies ensure the efficient of the transportation system and the management of traffic demand. Illegal parking practice can hamper sustainability of transportation system. This paper attempts to analyze the illegal parking behavior in Jeddah city, Saudi Arabia. Car parking in the city of Jeddah is largely uncontrolled and there is a lack of management of the public parking supply and controlled parking system. Parking survey at five main locations (roads) at Jeddah city was conducted. Legal and illegal parking were observed at the five roads. The observations were distributed over three time periods: 7:00-9:00 am period (morning peak), 12:00-15:00 pm period (afternoon peak) and 18:00-21:00 pm period (evening peak). The observations were collected, studied and compared for weekdays and weekend. Results indicate that illegal parking seems to be common in Jeddah city both on weekdays and weekend hampering the sustainability of transportation system. It is crucial for Jeddah city to deploy stringent parking policies in order to reduce the consequences of illegal parking behavior and to achieve sustainability in transportation.
\end{abstract}

\section{Keywords}

Parking, Illegal Parking, Drivers' Behavior, Jeddah

\section{Introduction}

Illegal parking has become a serious problem in Jeddah city in Saudi Arabia, causing undesirable traffic congestions, air, and noise pollutions and reducing ease of movement in and around the city. In fact, the rapid growth of vehicle ownership in Saudi Arabian cities, especially in Jeddah and the shortage of parking infrastructure, primarily proliferate the problem. Parking spaces play imperative role in the transportation system. A number of systems to manage and control, parking have been functioning and it has been perceived that the problem of parking is more serious in the central parts of 
the cities than the outer ones (Penfold, 2006).

Estimates of a number of studies (Shoup, 2006) prompt that the hunt for parking lots accounts for 30 percent of the city traffic in the peak period of the day. Irregular or illegal parking creates hurdles for the pedestrians who feel discomfort to walk as the walkways become discontinued (Khan \& Lourenço, 2010). Whatever is the reason behind parking constraints within a city boundary, the outcomes of these constraints are complicated (Shiftan, 2002; Shiftan \& Golani, 2005; Litman, 2008). There are also wide variations in the availability and demand of parking lots depending upon differences in space and time due to a range of bases (Levya \& Benenson, 2015).

Unfortunately, less attention was paid on parking trait in transport research till the 1990s (Ison \& Rye, 2006). Cheng (2013) has identified four key aspects that determine illegal parking, namely policy \& regulation, economic, social and technical. Lack of parking policy, incompetent regulations, and weak enforcement are included under policy \& regulation aspect. Economic aspect comprises the scenario because of rapid economic growth, changes in land uses and shortage in the adequate provision of parking lots. Social aspect consists, confronting mindset, lack of awareness and individual personality of a driver. While substandard design of parking lots, outdated signals, and ancillary parking furniture, along with non-adherence to the international quality standards, are subject to technical aspect, in fact a number of new and advanced technologies have been introduced for the efficient parking management such as radiofrequency identification (RFID) based intelligent parking assistant architecture (Barone et al., 2014), license plate recognition (LPR) based intelligent transportation systems (Tian et al., 2014), autonomous, distributed parking lot vacancy management using inter-vehicle communication (Yamashita \& Takami, 2014), intelligent management system of parking using wireless sensor network technology (Larisis, 2013) and many more.

Until recent past, transport planners believed that emergent vehicle ownerships should be supported by the corresponding increase in the supply of parking lots (Willson, 2013). While it was realized later on that expansion in the supply of parking lots have certain limitations which have steered an innovative concept known as "maximal parking supply". This model motivates urban residents to use public transport modes most often (Kodransky \& Hermann, 2011).

Al-Fouzan (2012) studied car parking standard requirements on the basis of different types of land uses in the United Kingdom, the United States of America, and Saudi Arabia. Provided that transportation planners in the United Kingdom and the United States of America retains robust and well capable of parking policies, particularly the use of car parking standards, in conjunction with other transport and planning measures, in order to encourage sustainable choices of transport to decrease private vehicle dependence and to decrease traffic congestion and subsequently air pollution. Al-Fouzan (2012) point out that, local authorities in the United Kingdom and United States of America have achieved the maximum parking standards which aim to reduce the number of private vehicles trips while maintaining the viability of sustainable develop- 
ment. However, local authorities in Saudi Arabia still apply the minimum standards for parking.

This paper attempts to analyze the illegal parking behavior in Jeddah city, Saudi Arabia. Car parking in the city of Jeddah is largely uncontrolled and there is a lack of management of the public parking supply and controlled parking system. The paper is organized as follows. Section 2 introduces general background about parking, illegal parking and parking in Saudi Arabia. Section 3 describes the methods used to carry out this study. Section 4 presents the study main results. Section 4 discusses the implications of the main results for parking management and transportation planning. Section 5 illustrates the conclusions and points at direction for future research.

\section{Background}

Financial and urban advancement in the Saudi Arabia has had a significant effect on the Saudis lifestyle. High income level has facilitated the increase of car ownership rates and thus has increased the private vehicle reliance for transportation. This has been triggered by vast spatial expansions of urban areas and deficient public transportation systems. At the beginning of the rapid expansion of Saudi cities, car parking has never created any problems. Currently, it is a common problem confronts local authorities in the major Saudi cities as a result of a rapid population growth and increased rates of car ownership. The car parking has turn into the main part in urban transportation arranging as a result of its connection to diverse exercises, area use, walker development, open transportation stations and street systems. Major Saudi cities in the Saudi Arabia experience parking problems where car parking provision is not associated with land use planning, In fact, the requirements for parking provision in different Saudi cities do not replicate the different land uses or and differences in density (Al-Fouzan, 2012).

Parking policy is the link amid transport policies and land use policies in an urban area or city (Marsden, 2006). Different municipalities have adopted a different criterion for the land use allocation requited for parking lots. For example, some municipalities use land area of the building to calculate required number of parking. This, in general, generates large areas for parking but in turn, induce load to city management. Therefore, vast parking spaces are available in the Saudi cities which necessitate a transform in the parking policy which stimulates sustainable transportation (Al-Fouzan, 2012). In fact, car parking is generally free, with vast on-street parking spaces provided on all main roads located in line with the linear commercial development. For charge car parking, the value of the parking congestion externality used to determine the parking fee (Arnott et al., 1999). In prevalent business regions and at peak times of the day, auto stopping is hard to find, in spite of the amounts accessible, which prompts another activity issue. In addition to that, on-street parking is used for employee parking, which worsens the parking problem (Al-Fouzan, 2012). Also, that a parking choice model is an important step towards the development of parking demand assignment models and to evaluate parking policies for the reduction of traffic network congestion (Ottomanelli, 2011). 
There are four factors that affect the illegal parking as follows: lack of national policy and deficiency in local regulations, rapid economic growth and inadequate provision of parking infrastructure, bad social habits as well as out of data techniques in building parking facilities and parking management (Spiliopoulou \& Antoniou, 2012). Accordingly, the effective parking policy and regulation, better education and advanced strategies are more helpful in solving the problem. Parking approach in a city is required to ensure that simplicity and road safety which facilities the sustainability of transport and encourage sustainable growth (Spiliopoulou \& Antoniou, 2012). If any parking system becomes more controlled and restricted, the referring traffic, environmental and monetary effects worsen in the short term. And introducing a control system on the capacity of the parking areas or imposing a parking fee will expectedly contribute, to transference from private to public transport and to other sustainable transportation solutions on the medium and long term (Costa et al., 2014). In the other hand, the main likely factors that affect the preference of the choice of parking location are security, available parking space, comfortability and closeness of parking place to the destination (Teknomo \& Hikao, 1997). With all considerations, a comprehensive program of parking management that includes integrated cost effective strategies can typically decrease the required parking amount at a destination by $20 \%$ to $40 \%$ while offering many added both social and economic benefits (Litman, 2008).

\section{Methodology}

\subsection{Study Area}

Jeddah city is one of the largest cities in Saudi Arabia. It is located in the middle of the eastern shore of Red Sea at the west of Saudi Arabia (Figure 1).

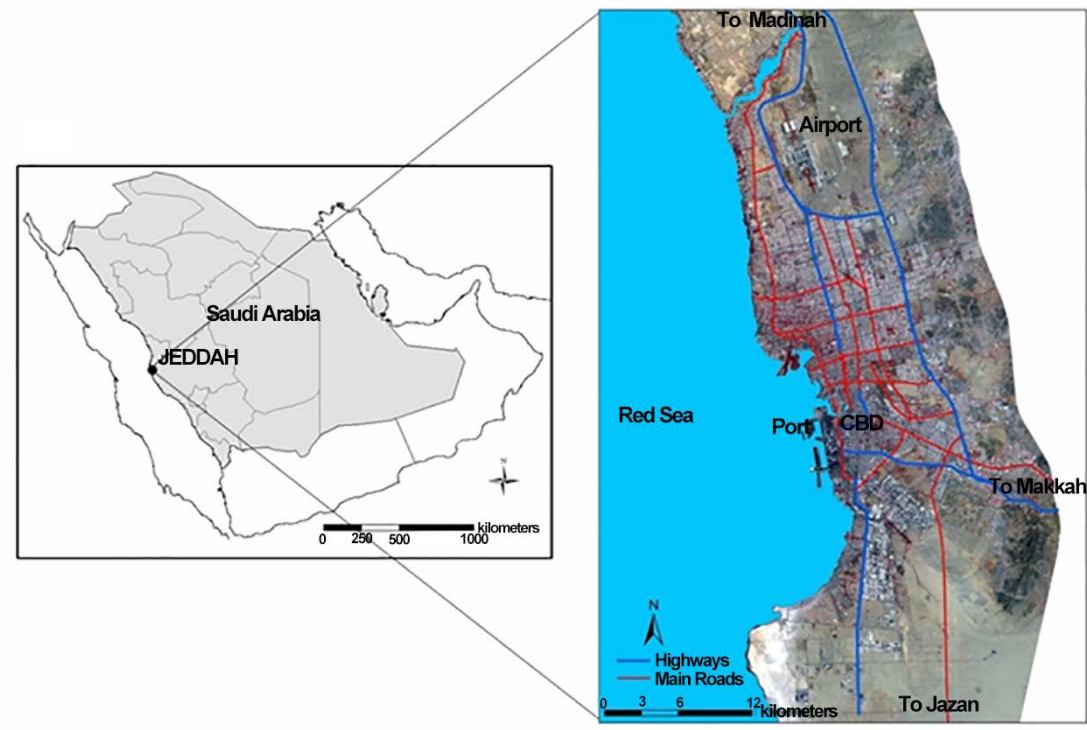

(a)

(b)

Figure 1. (a) Geographic location of Jeddah in Saudi Arabia; (b) Jeddah city. 
Jeddah's has undergone a rapid urban growth since 1960. Jeddah population has increased significantly from about 147,900 residents in 1964 to about 3,247,134 residents in 2007 (Aljoufie et al., 2013). Jeddah's transport is car dominant wherein 93\% of daily trips done by car (IBI, 2007). Public transport is deficient and shares a very low percentage of daily trips. Car parking in the city of Jeddah is largely uncontrolled and there is no management of the public parking supply. Inadequate car parking stimulates the uncontrolled use of the highways and main roads for stopping and loading and this affects the free-flow of traffic in different areas such as the city center and major retail corridors. Yet, there is a lack of studied and research about this issue.

\subsection{Parking Survey}

For the objective of this study, parking survey at five main critical locations (Figure 2) at Jeddah city was conducted. These locations are dominated by commercial land use and characterized by mix activities. Table 1 summarizes the main land uses of each of these locations. Legal and illegal parking were observed at the five roads. The number of parked vehicles legally and illegally was counted for each of the survey locations. The observations were distributed over three time periods: 7:00-9:00 am period (morning peak), 12:00-15:00 pm period (afternoon peak) and 18:00-21:00 pm period (evening peak). The observations were collected studied and compared for weekdays and weekend. These observations show the parking demand and facilitate the comparison of the fluctuations of legal and illegal parking behaviors directly.

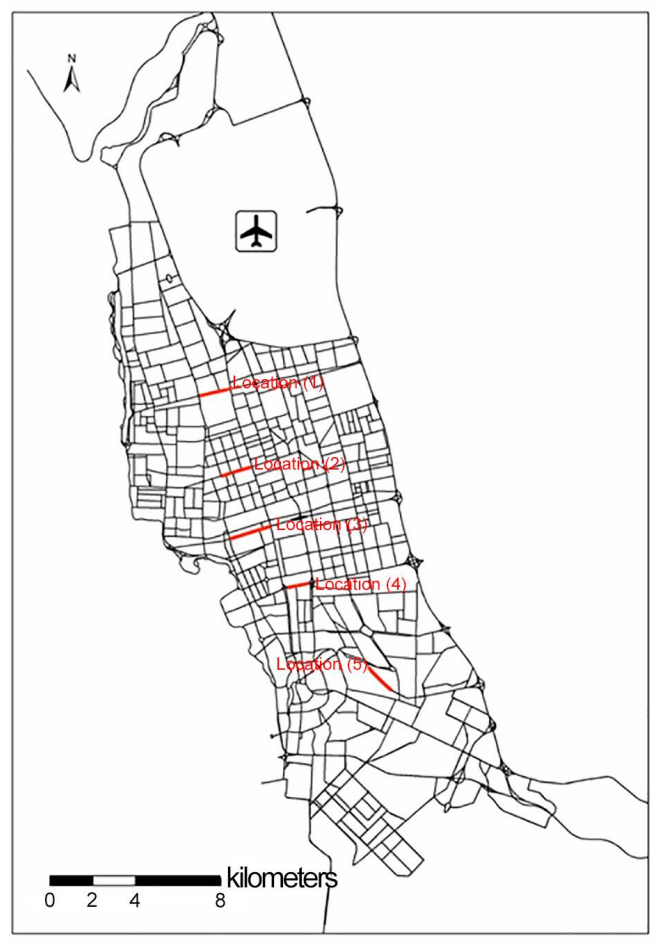

Figure 2. Distribution of the five examined locations in Jeddah City. 


\section{Results}

\subsection{Hira Street}

Figure 3 and Figure 4 present the observed parking condition diagrams for the Hirai Street during weekdays. Parking is free of charge in this location. During the weekday's period, illegal parking increases gradually at periods from 12:00 to 15:00 pm (afternoon peak) to 18:00 to 21:00 pm. Figure 5 and Figure 6 present the observed parking condition diagrams for the Hira Street during the weekend. Observations indicate that during the weekend illegal parking rises more than weekdays. The pattern and percentage of illegal parking in weekdays is different as compared to the weekend. It is noted that, during the weekend, illegal parking increases more as compared to legal parking, particularly in evening time (18:00 to $21: 00 \mathrm{pm}$ ). This can be attributed to the fact that this period is the peak shopping period during the weekend.

Table 1. Main land uses for the five examined locations in Jeddah City.

\begin{tabular}{ccc}
\hline Location & Name & Primary Land Uses \\
\hline-1 & Hira Street & Commercial/Services \\
-2 & Sari Street & Commercial/Services \\
-3 & Prince Mohammed bin Abdulaziz Street & Commercial \\
-4 & Palestine Street & Commercial \\
-5 & Abdullah Alsuliman Street & Commercial/Residential \\
\hline
\end{tabular}

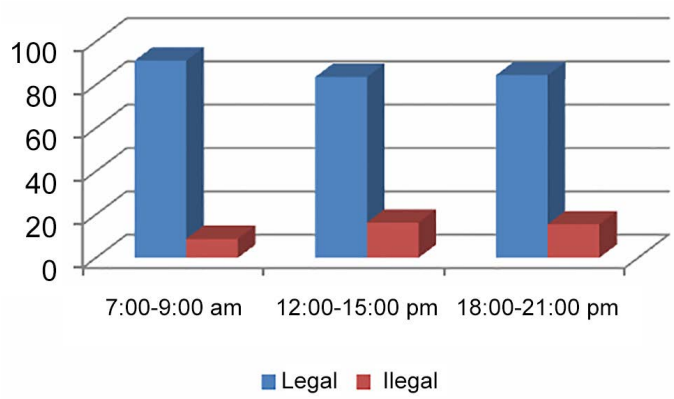

Figure 3. Percentage of legal parking and illegal parking at Hira Street during weekdays.

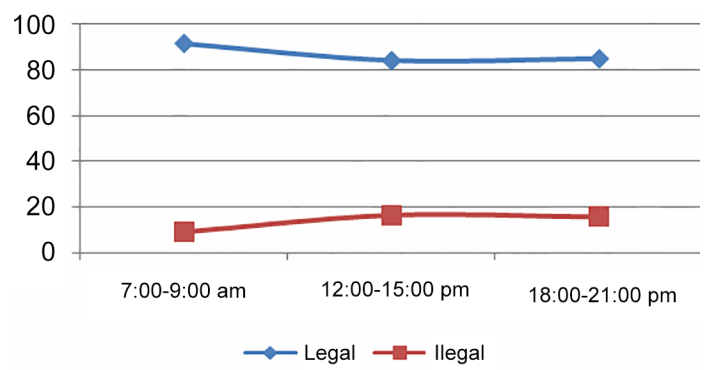

Figure 4. Legal parking and illegal parking accumulation pattern at Hira Street during weekdays. 


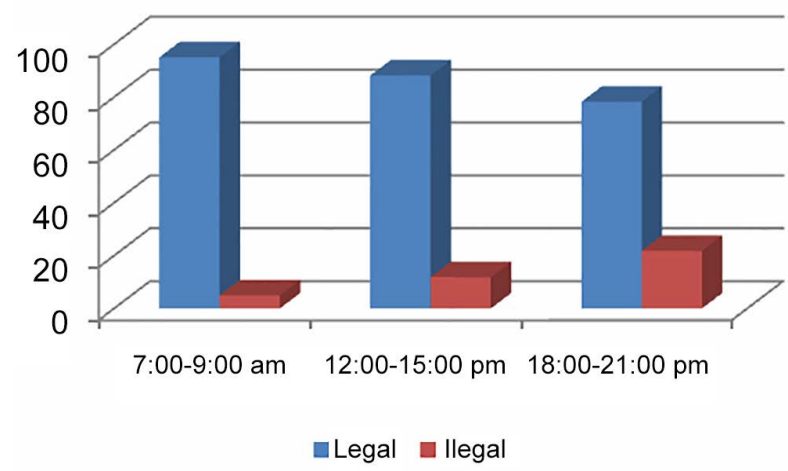

Figure 5. Percentage of legal parking and illegal parking at Hira Street during weekend.

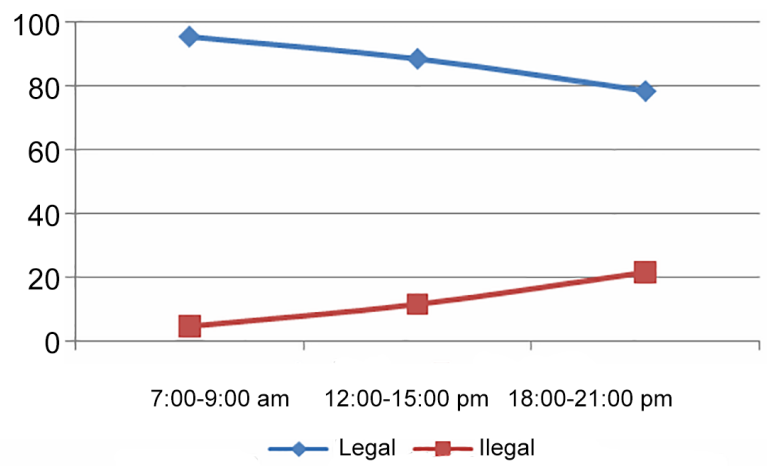

Figure 6. Legal parking and illegal parking accumulation pattern at Hira Street during weekend.

\subsection{Sari Street}

Figure 7, Figure 8, Figure 9 and Figure 10 illustrate the observed parking condition diagrams for Sari Street during weekdays and weekends respectively. Parking is free of charge in this location. During weekdays, illegal parking tends to increases from 7:00 to 9:00 am (morning peak) and from 18:00 to 21:00 pm. During the weekend illegal parking increases gradually at periods from 12:00 to 15:00 pm (afternoon peak) and from 18:00 to $21: 00 \mathrm{pm}$. It is noticed that both legal parking and illegal parking increases during weekend more as compared to weekdays particularly in the evening period (18:00 to 21:00 pm). This seems to be related shopping pattern in Jeddah wherein residents go to work and shopping in commercial area nearby and at the weekend, the road parking gets an additional visit from the other residents of other areas in Jeddah city.

\subsection{Palestine Street}

Figure 11 and Figure 12 presents the observed parking condition diagrams for the Palestine Street during weekdays. Parking is free of charge in this location also. At Palestine Street, during the weekday's illegal parking tend to increase gradually from 7:00 to 9:00 am (morning peak) and from 17:00 to 21:00 pm. Figure 13 and Figure 14 present the observed parking condition diagrams for the Palestine Street during the weekend. 
During the weekend, illegal parking rises more than weekdays. Although, illegal parking tend to increase gradually from 7:00 to 9:00 am (morning peak), it increase significantly from 18:00 to 21:00 pm. This can be attributed to the fact this road considers the mobiles and telecommunication hub in Jeddah wherein many residents all over Jeddah come to. A positive relationship between legal parking and illegal parking is noted during the weekdays and weekend especially in evening peak period (18:00 to 21:00 pm).

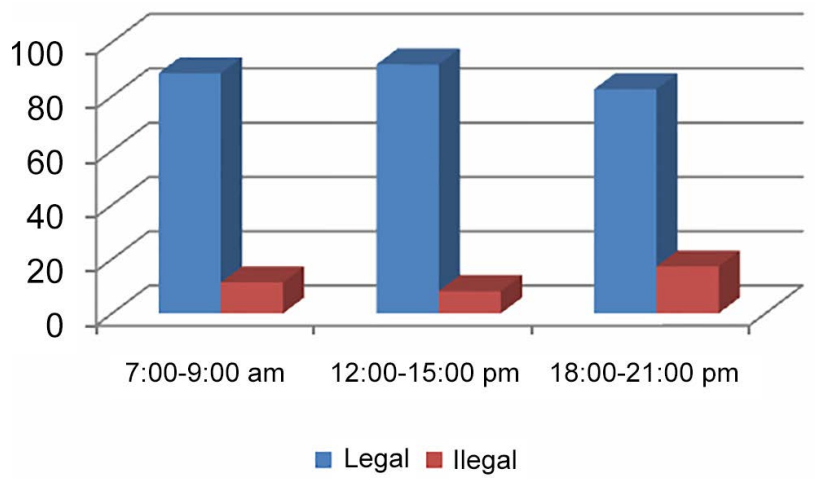

Figure 7. Percentage of legal parking and illegal parking at Sari Street during weekdays.

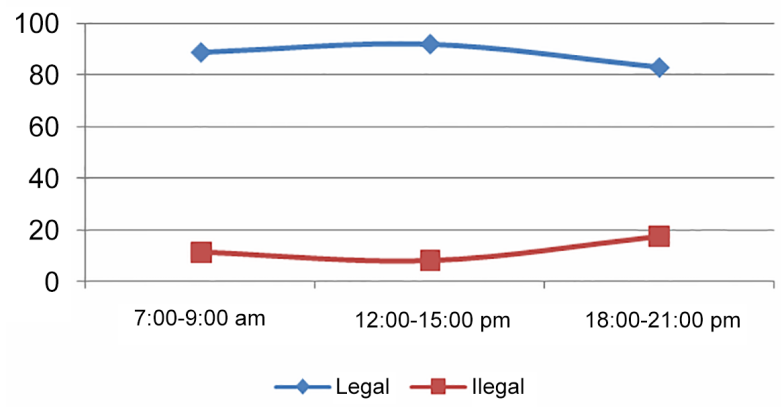

Figure 8. Legal parking and illegal parking accumulation pattern at Sari Street during weekdays.

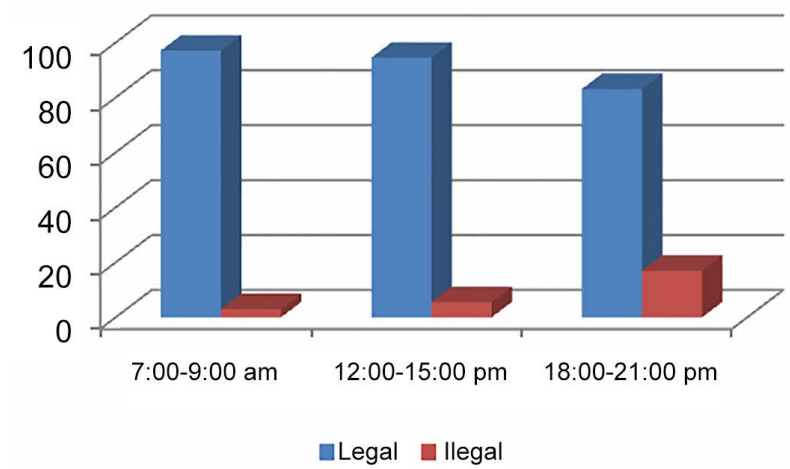

Figure 9. Percentage of legal parking and illegal parking at Sari Street during weekend. 


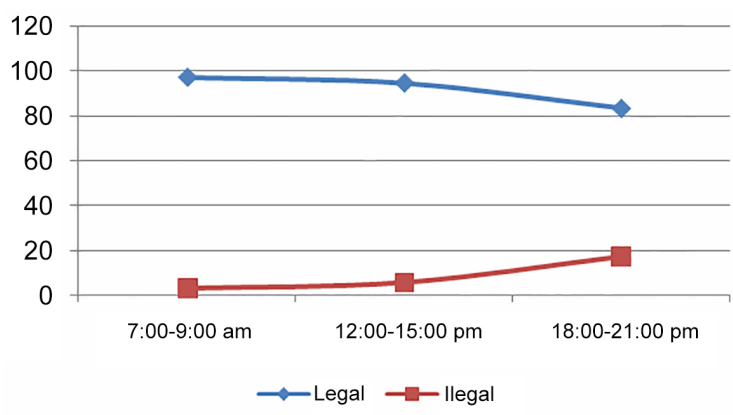

Figure 10. Legal parking and illegal parking accumulation pattern at Sari Street during weekend.

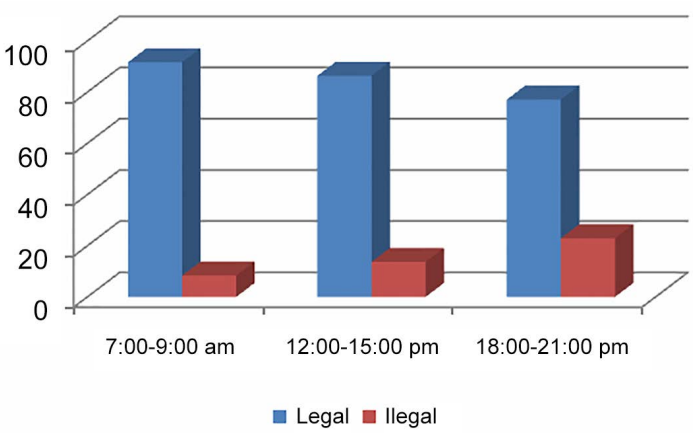

Figure 11. Percentage of legal parking and illegal parking at Palestine Street during weekdays.

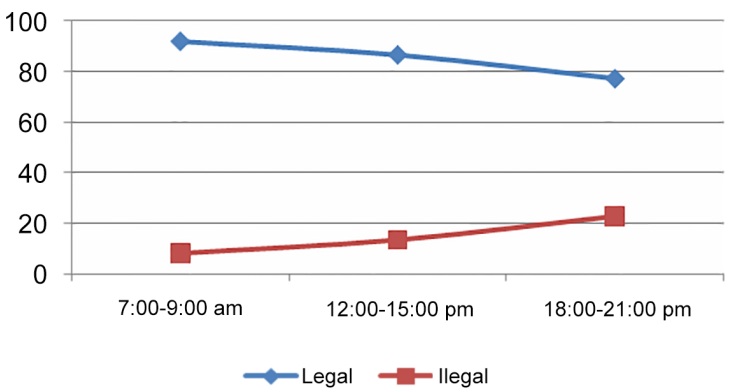

Figure 12. Legal parking and illegal parking accumulation pattern at Palestine Street during weekdays.

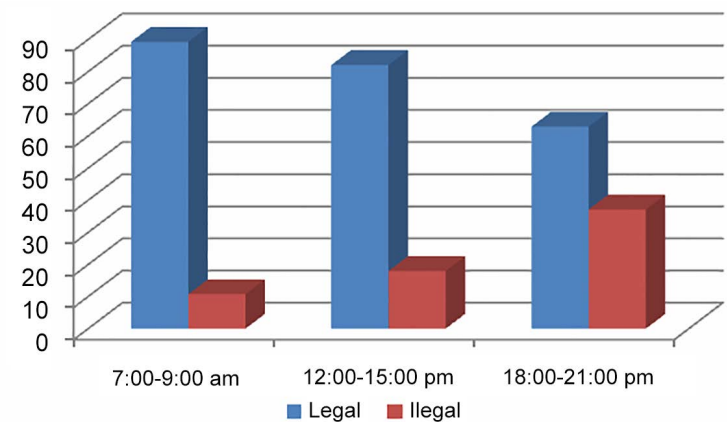

Figure 13. Percentage of legal parking and illegal parking at Palestine Street during weekend. 


\subsection{Prince Mohammed Bin Abdulaziz Street}

Figure 15, Figure 16, Figure 17 and Figure 18 show the observed parking condition diagrams for the Prince Mohammed bin Abdulaziz Street during weekdays and weekend. Parking is free of charge in this Location. At Prince Mohammed bin Abdulaziz Street, during the weekday's period, the demand for parking supply increases after 12:00 pm. The illegal parking increases during the period from 18:00 to 21:00 pm. During the weekend period, illegal parking increases more as compared to weekdays and

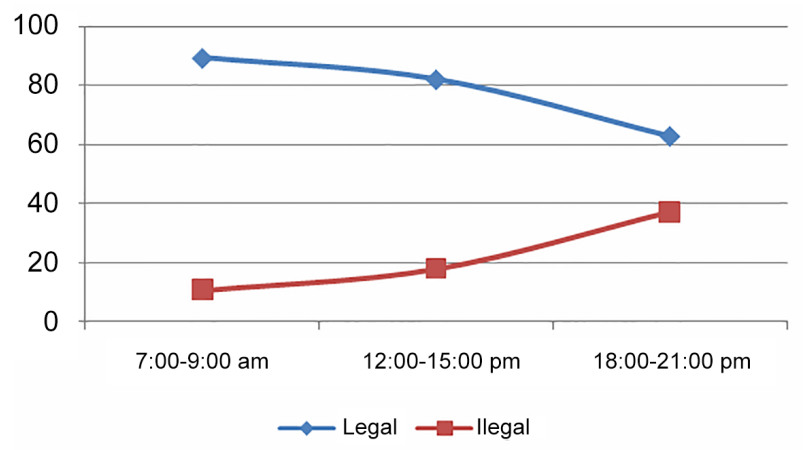

Figure 14. Legal parking and illegal parking accumulation pattern at Palestine Street during weeken.

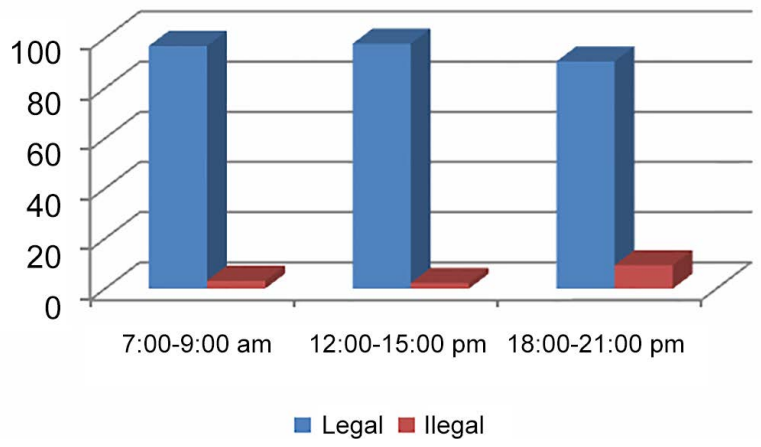

Figure 15. Percentage of legal parking and illegal parking at Prince Mohammed bin Abdulaziz Street during weekdays.

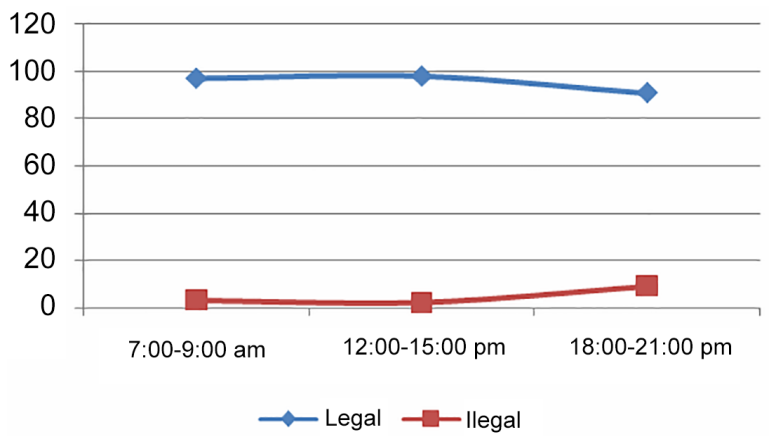

Figure 16. Legal parking and illegal parking accumulation pattern at Prince Mohammed bin Abdulaziz Street during weekdays. 


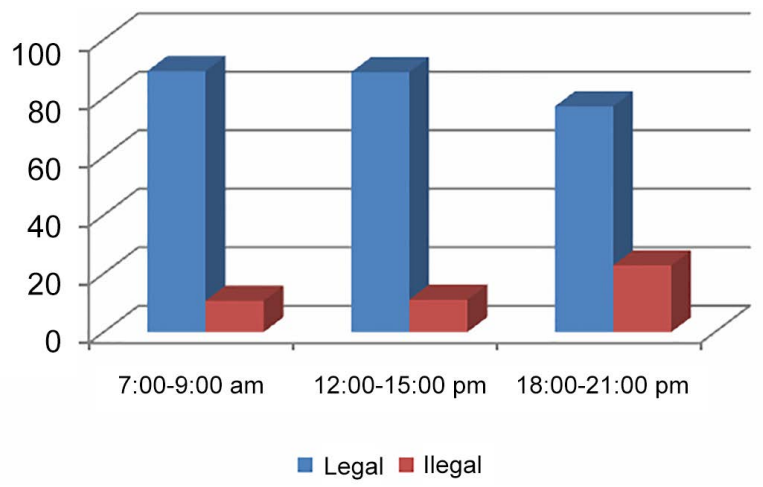

Figure 17. Percentage of legal parking and illegal parking at Prince Mohammed bin Abdulaziz Street during weekend.

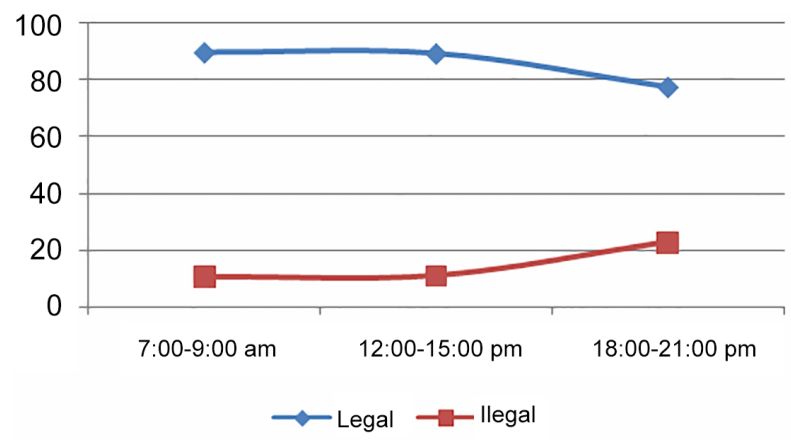

Figure 18. Legal parking and illegal parking accumulation pattern at Prince Mohammed bin Abdulaziz Street during weekend.

concentrated during the period from 18:00 to $21: 00 \mathrm{pm}$. It is noted that the pattern of illegal parking is similar in both weekend and weekdays periods which can be attributed to the land use in this area which dominated by commercial centers that have almost the peak pattern in the weekdays and weekend.

\subsection{Abdullah Alsuliman Street}

Figure 19 and Figure 20 presents the observed parking condition diagrams for the Abdullah Alsuliman Street during weekdays. Parking is free of charge in this location also. During the weekdays, illegal parking tends to be the same at the three periods (7:00 to 9:00 am, 12:00-15:00 pm, and 18:00 to 21:00 pm). This can be related to the existence of different land uses that which have different parking demand periods. Figure 21 and Figure 22 present the observed parking condition diagrams for Abdullah Alsuliman Street during the weekend. During the weekend, illegal parking rises more than weekdays. Although, illegal parking tend to increase gradually from 7:00 to 9:00 am (morning peak), it increase significantly from 18:00 to 21:00 pm. This can be attributed to the commercial activities in this road. Interestingly, Two different patterns of illegal parking during weekdays and weekend can be noted which seem to be highly related to the multi land uses in this road. 


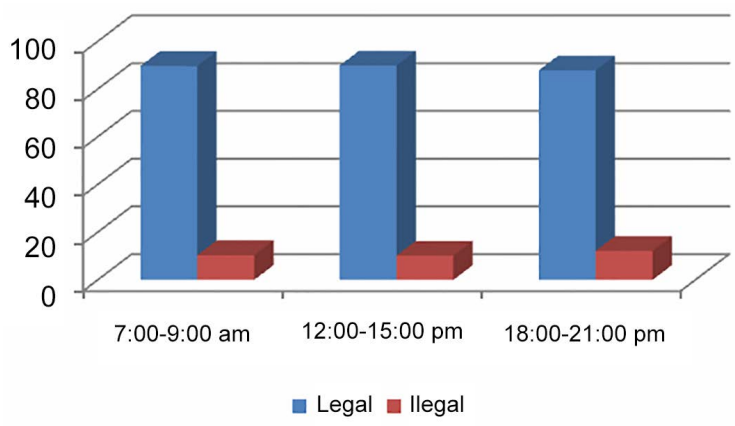

Figure 19. Percentage of legal parking and illegal parking at Abdullah Alsuliman Street during weekdays.

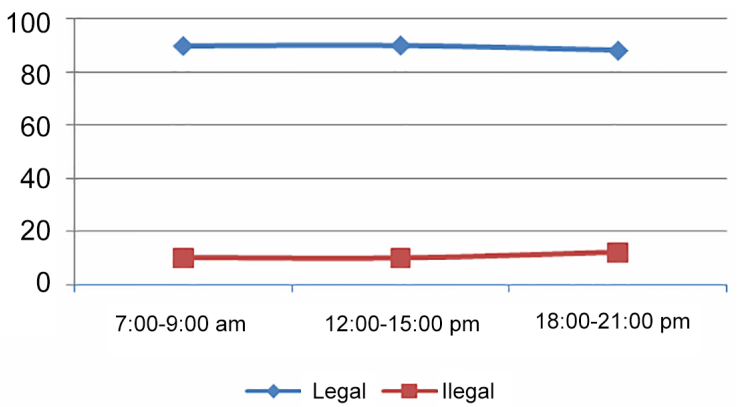

Figure 20. Legal parking and illegal parking accumulation pattern at Abdullah Alsuliman Street during weekdays.

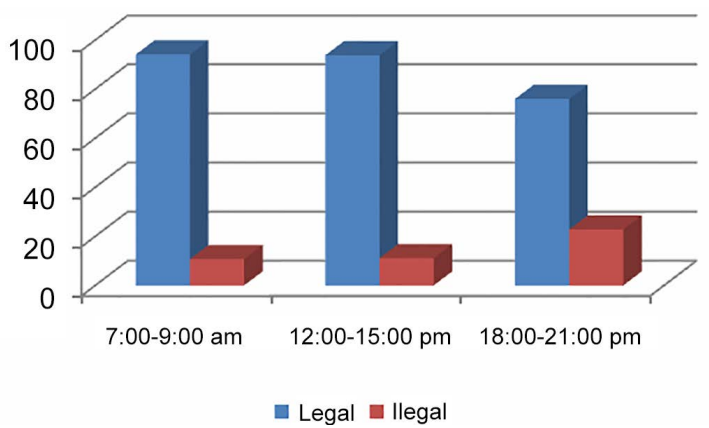

Figure 21. Percentage of legal parking and illegal parking at Abdullah Alsuliman Street during weekend.

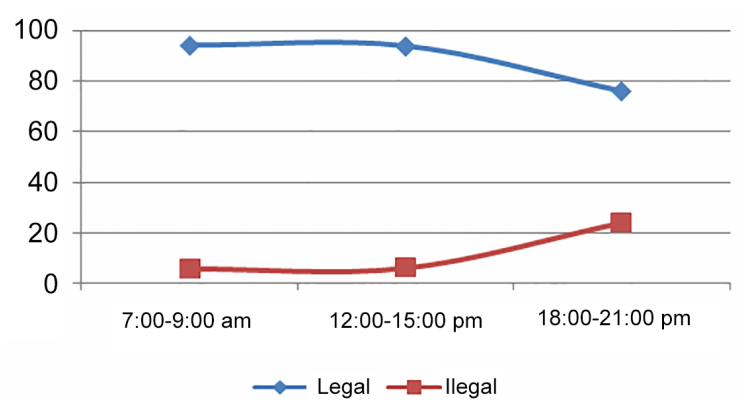

Figure 22. Legal parking and illegal parking accumulation pattern at Abdullah Alsuliman Street during weekend. 


\section{Discussion}

Results indicate that illegal parking seems to be common in Jeddah city both on weekdays and weekend. Illegal parking has been observed in all the five roads in Jeddah. However, it is noted that illegal parking increase more in the weekend period as compared to the weekdays. This can be related to the pattern of activities in the selected roads which receive visitors from all over Jeddah and urban peripheries. Moreover, there seems to be a positive relationship between legal and legal parking and illegal parking. As the demand for parking increase, illegal parking increase accordingly. It noted that the evening peak period from $18: 00$ to $21: 00 \mathrm{pm}$ is the most significant time where illegal parking is observed. This period is the peak shopping period both in the weekdays and in the weekend. Most of the people are off work and study during this period. Interestingly, illegal parking is noted also during morning peak period (7:00 to 9:00 am) and afternoon peak period.

Although, illegal parking is highly related to the high demand for parking (legal) and lack of infrastructure in some of the investigated locations there seem to be apathetic behavior of the drivers. This can be justified by the observed illegal parking in different periods even when the demand for (legal) is low. In fact, the traffic police and Jeddah municipality holds the authority to control car parking. In essence, there is a lack of an efficient parking policy and the parking management practice well in place. Generally, the parking is free in the city and on-street parking is provided on all major roads that are located adjacent to the commercial activities, except some location in the city center (Albalad). Although, the increasingly of growth of vehicle ownership becoming a problem in parking capacity and convenience. Regulations already exist but the level of enforcement is still lacking, some drivers still violate the regulations. Regulations could be many, but if it is not based on the driver's awareness of the benefits are less pronounced. There is a need for teaching and awareness of the importance of manners in the drive, including the procedures and regulations for parking. Use of parking signs is important when vehicles do park on the road parking. The driver will see clearly limits the area where he could park or not. Thus, there is a lack of these signs in most of the investigated roads. The illegal parking seem occurs in Jeddah because the current mechanism of levying penalty is so poor, while the practice of illegal parking behaviour of drivers is too common; who even do not realise that it might be a serious violation of traffic regulations; while there are studies that treat traffic violators as criminal (Jose et al., 2015).

During the observation at the five different roads, a personal habit of the drivers to park closest to the activity has been noticed. Drivers prefer to park illegally near the trip destination activity rather than parking at the further shorter distance or at a long term parking zone. Double parking almost is a daily experience at all the five roads, particularly during the peak periods. Undeniably this has consequences for traffic flow and results in congestion. Inefficient management of parking demand significantly contributes to urban congestion (Calthrop et al., 2000). In fact, double parking block lanes that would be used by other moving traffic and limit road capacity. In addition to that, 
parking maneuver delays the traffic flow and reduce the speed and capacity of the other lanes (Cats et al., 2016).

High parking duration has been noticed also during the observation, particularly in roads with residential/commercial land use. Certainly this has been catalyzed by the absence of parking policies. In essence, the city's parking policies must be supported by real action is realized through the controlled parking system. Poor driver habits expected with this system can improve the level of discipline. Almost all street parking spot is not using this system. As such, parking pricing proved to be imperative policy instrument to contain the traffic and parking problems (Cats et al., 2016). In fact, an efficient management of parking demand can effectively utilize the parking space and limited capacity in areas with high demand. Previous studies point out the role of on-street parking regulations and policies such as imposing fees or enforcing parking duration as measures to decrease traffic congestion and manage the parking demand (Albert \& Mahalel, 2006; Fosgerau \& de Palma, 2013).

\section{Conclusion}

Parking practice in Jeddah is not healthy and hampers sustainability of transportation. Illegal parking seems to be common in Jeddah city both on weekdays and weekend but rises more in the weekend. The evening peak period from 18:00 to $21: 00 \mathrm{pm}$ is the most significant time where illegal parking is observed in all the five roads. Drivers tend to park illegally closest to the destination even if legal parking available at a further distance. Commercial activities seem to catalyze the demand for parking. However, in general, there is no shortage of the availability of parking lots in the majority of locations the illegal parking occurs because of either the careless behavior of drivers or due to the poor mechanism of levying a penalty. In addition to that; there is a lack of driver's awareness. Parking signs as such were limited throughout the investigated roads.

It is crucial for Jeddah to deploy stringent parking policies in order to reduce illegal parking behavior. These days a variety of parking policies are available to ensure efficient management of parking demand which in turn can improve the utilization the parking space and limited capacity in areas with high demand and reduce the problems caused by parking. The necessities ought to be intended to be a piece of an arrangement of methods to reduce the reliance of private vehicle and need for it, to improve the alternatives for sustainable transport, to reduce traffic congestion, and to enhance the mobility at urban areas. Further research to examine the effect of these measures on illegal parking behavior is recommended.

\section{References}

Albert, G., \& Mahalel, D. (2006). Congestion Tolls and Parking Fees: A Comparison of the Potential Effect on Travel Behavior. Transport Policy, 13, 496-502.

http://dx.doi.org/10.1016/j.tranpol.2006.05.007

Al-Fouzan, S. (2012). Using Car Parking Requirements to Promote Sustainable Transport Development in the Kingdom of Saudi Arabia. Cities, 29, 201-211.

http://dx.doi.org/10.1016/j.cities.2011.08.009 
Aljoufie, M., Zuidgeest, M., Brussel, M., \& Van Maarseveen, M. (2013). Spatial-Temporal Analysis of Urban Growth and Transportation in Jeddah City, Saudi Arabia. Cities, 31, 57-68. http://dx.doi.org/10.1016/j.cities.2012.04.008

Arnott, R., \& Rowse, J. (1999). Modeling Parking. Journal of Urban Economics, 45, 97-124. http://dx.doi.org/10.1006/juec.1998.2084

Barone, R. E., Giuffrè, T., Siniscalchi, S. M., Morgano, M. A., \& Tesoriere, G. (2014). Architecture for Parking Management in Smart Cities. IET Intelligent Transport Systems, 8, 445-452. http://dx.doi.org/10.1049/iet-its.2013.0045

Calthrop, E., Proost, S., \& Van Dender, K. (2000). Parking Policies and Road Pricing. Urban Studies, 37, 63-76. http://dx.doi.org/10.1080/0042098002294

Cats, O., Zhang, C., \& Nissan, A. (2016). Survey Methodology for Measuring Parking Occupancy: Impacts of an On-Street Parking Pricing Scheme in an Urban Center. Transport Policy, 47, 55-63. http://dx.doi.org/10.1016/j.tranpol.2015.12.008

Cheng, J. ( 2013). Analysis of Illegal Parking: A Case Study on Hefei. Diss. Pokfulam, Hong Kong: The University of Hong Kong.

Costa, Á., Rocha, C., \& Melo, S. (2014). Parking Management Policies and the Effectiveness of Public Policy Solutions. Procedia-Social and Behavioral Sciences, 111, 965-973.

http://dx.doi.org/10.1016/j.sbspro.2014.01.131

Fosgerau, M., \& de Palma, A. (2013). The Dynamics of Urban Traffic Congestion and the Price of Parking. Journal of Public Economics, 105, 106-115.

http://dx.doi.org/10.1016/j.jpubeco.2013.06.008

IBI, G. (2007). Jeddah Public Transportation Study. Saudi Arabia: Ministry of Transportation.

Ison, S., \& Rye, T. (2006). Parking: Editorial. Transport Policy, 13, 445-446. http://dx.doi.org/10.1016/j.tranpol.2006.05.001

Jose, I. C. M., Mercedes, C. N., \& Xavier, F. (2015). Are Traffic Violators Criminals? Searching for Answers in the Experiences of European Countries. Transport Policy, 38, 86-94. http://dx.doi.org/10.1016/j.tranpol.2014.12.003

Khan, R. R., \& Lourenço, J. M. (2010). Pedestrian Planning in City Centers: a Study of Guimarães and Braga. TeMA: Journal of Land Use, 3, 37-46.

Kodransky, M., \& Hermann, G. (2011). Europe's Parking U-Turn: From Accommodation to Regulation. New York: Institute for Transportation and Development Policy.

Larisis, N., Perlepes, L., Stamoulis, G., \& Kikiras, P. (2013). Intelligent Parking Management System Based on Wireless Sensor Network Technology. Sensors \& Transducers, 18, 100-112.

Levya, N., \& Benenson, I. (2015). GIS-Based Method for Assessing City Parking Patterns. Journal of Transport Geography, 46, 220-231. http://dx.doi.org/10.1016/j.jtrangeo.2015.06.015

Litman, T. (2008). Parking Management-Strategies, Evaluation and Planning. Victoria Transportation Institute. (available at: www.vtpi.org)

Marsden, G. (2006) The Evidence Base for Parking Policies-A Review. Transport Policy, 13, 447-457. http://dx.doi.org/10.1016/j.tranpol.2006.05.009

Ottomanelli, M., Dell'Orco, M., \& Sassanelli, D. (2011). Modelling Parking Choice Behaviour Using Possibility Theory. Transportation Planning and Technology, 34, 647-667. http://dx.doi.org/10.1080/03081060.2011.602846

Penfold, S. (2006). Lots of Parking: Land Use in Car Culture. Urban History Review, 34, 58. http://dx.doi.org/10.7202/1016014ar

Shiftan, Y., \& Golani, A. (2005). Effects of Auto Restrain Policies on Travel Behaviour. Transportation Research Record, 1932, 156-163. http://dx.doi.org/10.3141/1932-18 
Shiftan, Y. (2002). The Effects of Parking Pricing and Supply on Travel Patterns to a Major Business District. In E. Stern, I. Salomon, \& P. H. L. Bovy (Eds.), Travel Behaviour: Spatial Patterns, Congestion and Modelling (pp. 37-52). Cheltenham: Edward Elgar Publishing.

Shoup, D. (2006). Cruising for Parking. Transport Policy, 13, 479-486. http://dx.doi.org/10.1016/j.tranpol.2006.05.005

Spiliopoulou, C., \& Antoniou, C. (2012). Analysis of Illegal Parking Behavior in Greece. Procedia-Social and Behavioral Sciences, 48, 1622-1631. http://dx.doi.org/10.1016/j.sbspro.2012.06.1137

Teknomo, K., \& Kazunori, H. (1997). Parking Behavior in Central Business District a Study Case Of Surabaya, Indonesia. Easts Journal, 2, 551-570.

Tian, Q., Guo, T., Qiao, S., Wei, Y., \& Fei, W. (2014). Design of Intelligent Parking Management System Based on License Plate Recognition. Journal of Multimedia, 9, 774-780. http://dx.doi.org/10.4304/jmm.9.6.774-780

Willson, R. W. (2013). Parking Reform Made Easy (p. 272). Washington DC: Island Press.

Yamashita, S., \& Takami, K. (2014). Autonomous, Distributed Parking Lot Vacancy Management Using Inter Vehicle Communication. International Journal of Vehicular Technology, 2014, Article ID: 647487. http://dx.doi.org/10.1155/2014/647487

Submit or recommend next manuscript to SCIRP and we will provide best service for you:

Accepting pre-submission inquiries through Email, Facebook, LinkedIn, Twitter, etc. A wide selection of journals (inclusive of 9 subjects, more than 200 journals)

Providing 24-hour high-quality service

User-friendly online submission system

Fair and swift peer-review system

Efficient typesetting and proofreading procedure

Display of the result of downloads and visits, as well as the number of cited articles

Maximum dissemination of your research work

Submit your manuscript at: http://papersubmission.scirp.org/

Or contact cus@scirp.org 